\title{
Low Carbon Distribution Channel Coordination with a Capital-Constrained Retailer
}

\author{
Jun Wang $\mathbb{D},{ }^{1}$ Xianxue Cheng $\mathbb{D},{ }^{1}$ and Shuhua Zhang $\mathbb{D}^{1,2}$ \\ ${ }^{1}$ School of Management Science and Engineering, Tianjin University of Finance and Economics, Tianjin 300222, China \\ ${ }^{2}$ Coordinated Innovation Center for Computable Modeling in Management Science, \\ Tianjin University of Finance and Economics, Tianjin 300222, China
}

Correspondence should be addressed to Shuhua Zhang; shuhua55@126.com

Received 13 March 2018; Revised 27 June 2018; Accepted 5 July 2018; Published 1 August 2018

Academic Editor: Filippo Cacace

Copyright (c) 2018 Jun Wang et al. This is an open access article distributed under the Creative Commons Attribution License, which permits unrestricted use, distribution, and reproduction in any medium, provided the original work is properly cited.

\begin{abstract}
Capital constraints exist in many supply chains. We examine a low carbon distribution channel that consists of a manufacturer and a retailer, in which the retailer is constrained by capital. The retailer can be financed by bank credit from a competitive bank market. A Stackelberg model is developed to analyze the integrated decision-making process of ordering, financing, and emission reduction. By comparing the decentralized and centralized channels, we obtain that the manufacturer's green technology investment should be linearly proportional to the retailer's order quantity in both channels. Thus, a large order quantity leads to increased efforts to reduce emissions. Results further show that the centralized channel in some cases has fewer emissions and can generate more profits for the whole supply chain compared with the decentralized channel. We therefore propose a revenue sharing contract with a function form to coordinate the distribution channel. When the government allocates appropriate quotas to the supply chain, high carbon price can benefit the environment and supply chain efficiency.
\end{abstract}

\section{Introduction}

The industrial modernization has developed simultaneously with carbon emissions over the past decades, resulting in global warming, and challenges the survival of human beings. Global warming is at least $90 \%$ caused by human activities [1]. Therefore, we must change the mode of production to achieve a low carbon economy. However, this aspiration also challenges the supply chain management and has therefore attracted the attention of many researchers to study the optimization of operation strategy related to the reduction of carbon emissions. For the goal of carbon emission reduction, governments tend to implement regulation policies, in which the carbon cap-and-trade policy is effective in reducing carbon emissions without increasing costs significantly [2]. The policy achieves the goal of emission reduction by means of regulation and market. In the supply chain, the enterprise can treat the carbon emission permits as part of the operation cost. It can trade the permits or invest in green technology and process improvement to save the permits. The investment increases cost but can reduce carbon emissions and gain additional revenue through the sales of the savage of carbon emission permits.

Some enterprises reportedly face demand uncertainty when making decisions related to emission reduction, mainly because products increasingly have the property of short sale cycles, e.g., some traditional goods (food and cut flowers), fashionable goods (clothing), and high-tech products (mobile phones) $[3,4]$. Given the demand uncertainty, an enterprise finds deciding production/order quantity complicated, especially when it is a small- and medium-sized enterprise (SME) and when the salvage value of the product is small or even zero. Moreover, most SMEs suffer from the shortage of liquid funds after the global financial crisis. Such enterprises need financing to support daily production and sales operations [5]. Therefore, the interfaces of operations and financial decisions receive substantial interest in the field of supply chain management in recent years.

Most SMEs in a supply chain lack funds. The retailer needs funds for purchasing goods or sales promotion, and the manufacturer needs funds for production and distribution operations. Apart from the funding requirements of daily 
operations, low carbon investment needs extra funds. Thus, an SME needs to seek a loan. The most common way of financing is bank credit, which is a concern in this study.

The retail price of the product is assumed to be constant in the retail market in the context of carbon cap-andtrade policy. We develop a game model of the supply chain that consists of a manufacturer and a capital-constrained retailer with the newsvendor model. The manufacturer can invest in green technology to reduce carbon emissions per unit product. The retailer must make a decision on order quantity and then borrow from banks for payment. Three key questions are addressed in this study:

(1) In the decentralized supply chain setting, what are the optimal production quantity, carbon trading strategy, interest rate of bank credit, and green technology investment?

(2) In the centralized supply chain setting, what are the optimal strategies for the retailer, manufacturer, and banks?

(3) How can the decentralized supply chain be coordinated to achieve performance in the centralized setting scenario? What contract should be made?

The remainder of the paper is organized as follows. Section 2 reviews the associated literature. Section 3 presents the model descriptions, assumptions, and the decentralized supply chain setting model and obtains the optimal strategies for the manufacturer, retailer, and banks. Section 4 discusses the optimal strategies for the centralized decision-maker and the banks in the centralized supply chain setting. This section also designs a supply chain coordination mechanism and analyzes the model for the optimal strategies by comparing green technology investments and order quantities in two settings of the supply chain. Section 5 illustrates the numerical examples. Section 6 presents the conclusions of our findings and highlights possible future work.

\section{Literature Review}

This section reviews the related literature on the "interface of operations and financing decisions" and the "interface of operations and emission reduction decisions." We then highlight the integrated problem proposed in the literature referred to as "low carbon supply chain with capital constraints."

\subsection{Interface of Operations and Financing Decisions. In recent} years, many researchers have been concerned about the interface of operations and financing decisions in supply chain management. Zhao and Huchzermeier [6] reviewed the operation-finance interface from a closed loop view, presented a risk management framework, and gave dimensions and categories. The capital-constrained supply chain management problem has attracted wide attention. One of the first studies with capital constraints has been conducted in a newsvendor model by $\mathrm{Xu}$ and Birge [7]. Their study illustrated how a firm's capital constraints and capital structure affect production decisions.

Many studies have focused on the retailer's ordering/inventory strategy by incorporating the traditional way of financing, which is bank credit. In the completed competitive banking market, research has shown that capital constraints do not influence retailer's optimal decision $[8,9]$. On the contrary, capital constraints affect a retailer's strategy by using its internal capital and interest rate when it secures a loan from a noncompetitive banking market [10] or faces uncertainty demand in a price-dependent market [11, 12]. To avoid risks, banks always require a credit guarantee from the upstream manufacturer when they offer the SME retailer a loan. Yan et al. [13] suggested the credit guarantee can effectively balance the retailer's financing risk between the bank and the manufacturer through interest rate charging and wholesale pricing.

Another common way of a loaning is asset-based financing. Buzacott and Zhang [14] were the first to incorporate asset-based financing into production decisions. A bank can announce different interest rates on cash balance and outstanding loans, whereas retailers are at different capital levels. The result shows that the retailers can enhance their return with asset-based financing. Firms with limited capital can also seek a commercial loan from the external market to increase their budget. For example, Boyabatli and Toktay [15] studied the integration of operations and financial risk management decisions.

Trade credit financing is another common mode for a retailer to deal with a short-term budget shortage problem [16]. As an integrated part of a supply chain contract, trade credit can act as a risk-sharing mechanism among supply chain members [17]. Jing et al. [18] compared the efficiency between bank credit financing and trade credit financing for a capital-constrained retailer and found that trade credit financing becomes highly effective when production cost is relatively low. Chen [19] further studied the coordination problem in the supply chain. Bank versus trade credit is compared under revenue sharing contract, and the results show that channel coordination can create more profit for both channel members. Moreover, for any given revenue sharing rate, channel coordination requires a higher wholesale price under trade credit financing than under bank credit financing. Cai et al. [20] theoretically proved that the two credits are complementary if the retailer's internal capital is substantially low, but they become substitutable as the internal capital grows, and this prediction has been empirically validated. Yang and Birge [17] revealed that trade credit allows the manufacturer to take advantage of the retailer's lack of funds. Moreover, this setup may benefit both members when the retailer's financial situation is relatively strong. Another risk-sharing mechanism is option contract. By considering bankruptcy risk, Zhang et al. [21] studied pure option ordering and pricing decision problems. Their model demonstrated that the decisions and profits under bank credit do not depend on the initial capital and the default risk, but default risk has a significant impact on the results under trade credit.

During supply chain management, the manufacturer and supplier may also suffer from capital constraints if they are SMEs. For instance, Jiang and Hao [22] considered a manufacturer that sources from a capital-constrained supplier and offers advance payment to preorder a quantity that must be satisfied by the production of a supplier before the actual demand arises. They studied the effectiveness of 
such a two-order arrangement in alleviating the supplier's capital restriction on channel performance. To deal with the manufacturer's production capital constraints in the supply chain, Wang et al. [23] considered two financing modes, the retailer's prepayment financing mode and the procurement contract financing mode. They built a model with production and financing decision under two financing modes, and the results show that the two modes can bring new value and profit for the supply chain. The manufacturer and the retailer can also be capital-constrained. Yan et al. [24] designed a supply chain finance system, which considers the bankruptcy risks of the manufacturer and the retailer. They formulated a bi-level Stackelberg game in which the bank acts as the leader and the manufacturer acts as the subleader; they arrived at the conclusion that the different interest rates and credit lines can affect the supply chain operations. Kouvelis and Zhao [25] studied the impact of credit ratings on the operational and financial decisions of a supply chain where the retailer can use bank and trade credits for its financing needs while the supplier can use bank credits and the retailer's early payment. The authors provided insights into who should finance the supply chain and at what rates when there are differential credit ratings between the supply chain members.

\subsection{Interface of Operations and Emission Reduction Decisions.} In the background of low carbon economy, many studies of supply chain have focused on integrated decisions on operations and emission reductions. A manufacturer can invest in green technology to reduce carbon emissions in production. In a two-echelon supply chain system that consists of one manufacturer and one retailer, for example, Jiang and Chen [26] investigated the traditional operation decisions (including optimal production and pricing) and emission reduction decisions (including carbon trading and green technology investment) when the retailer faces stochastic demands formed by homogeneous strategic customers. The authors argued that quantity commitment strategy can improve the profit of the supply chain with strategic customer behavior. They also proved that the revenue sharing with cost sharing contract can coordinate the supply chain, as opposed to that with revenue sharing contract alone.

From the consumers' perspective, product demands may be carbon-sensitive in low carbon policies, and the consumers are assumed to prefer low carbon products. According to $\mathrm{Ma}$ et al. [27], the production strategies are discussed under carbon cap policy regulations and consider the two scenarios of deterministic demand and stochastic demand. They analyzed the influence of different low carbon-sensitive coefficients on manufacturing's profit. In a carbon-sensitive market, emission reduction takes the high production costs and stimulates the inverse demand function. Therefore, the participants of the supply chain should coordinate two objectives: carbon emission reduction and profit-seeking behavior. $\mathrm{Du}$ et al. [28] argued that the supply chain's profit and the emission reduction increase simultaneously in particular cases, and the manufacturer's optimal carbon emissions per unit product keep the same as those in the centralized channel regardless whether the supply chain is coordinated. In a two-echelon supply chain with carbon-sensitive products,
Wang et al. [29] developed a game model for the issues of carbon emission reduction within the retailer-dominant and the power-balanced cases. The authors found that the cost-sharing contracts in the retailer-dominant and powerbalanced cases can both result in the improved Pareto of the manufacturer's and the retailer's profits. Moreover, the supply chain meets uncertain demand, which is solved by forecasting. Qin et al. [30] discussed three demand forecasting settings: information sharing, full information sharing, and retailer-only forecasting.

In some application scenarios, the manufacturer and the retailer must make a decision on low carbon effort when both face a carbon-sensitive market. For example, $\mathrm{Du}$ et al. [31] developed a Stackelberg-like model to analyze the decisions of the manufacturer and retailer. They proposed a carbon-related price and discount sharing-like scheme to coordinate the channel for Pareto improvement. Some other studies were concerned with the supply chain with a supplier and a manufacturer. Xu et al. [32] studied the impacts of technological spillovers and environmental awareness to reduce carbon emission. The authors propose a bargaining-coordination contract through revenue-cost sharing to enhance performance and improve the profits of players as technological spillovers and environmental awareness increase. Another direction focuses on the dualchannel supply chain. For example, Chen et al. [33] analyzed the influences of the level of environmental sustainability of channels on the pricing policies for the supply chain members. Ji et al. [34] investigated the emission reduction behaviors for the supply chain members in the retail-channel and the dual-channel cases by using the Stackelberg game model. The other directions we surveyed are integrated into disciplines, which include marketing (e.g., in Bai et al. [35], the demand is affected by product selling price, low carbon level, and promotional effort) and finance (discussed in the following sections).

\subsection{Low Carbon Supply Chain with Capital Constraints. In} our survey, only a few researchers have been attracted by the integrated decisions of operations, emission reduction, and financing. For example, Wang et al. [36] examined manufacturing/remanufacturing planning problems when the manufacturer is capital-constrained. The results show that capital constraint can encourage the manufacturer to remanufacture used products at a high-quality level, reduce carbon emissions, and achieve the maximum profit when the manufacturer has sufficient capital financing from banks or capital markets. From the viewpoint of the supply chain, An and Yao [37] studied a two-echelon green supply chain by considering the situation of the manufacturer's capital constraint. They proposed the framework as a Stackelberg game led by the manufacturer, analyzed the equilibrium solution in the supply chain under the bank credit, and concluded that a hybrid contract of revenue share and buyback realizes channel coordination. They borrowed the concept of the green degree to describe the product attributes, and the development cost of the product is linear with the green degree. They did not consider the low carbon 
policies and emission reduction target. By contrast, in a capand-trade policy, Cao and $\mathrm{Yu}$ [38] concentrated on trade credit financing, whereas Yang et al. [39] focused on carbon financing. The former found that the manufacturer prefers to cooperate with a medium rich retailer, and a general coordinating contract (including revenue sharing, buy back, and quantity discount) can coordinate the supply chain. The latter studied the cooperation modes in the supply chain. The authors proposed the mode as "supply chain carbon finance," in which the manufacturer and the retailer share carbon emission quotas. In this cooperation mode, a carbon fund is built to apply for a green loan by using carbon quotas as collateral. This mode can improve the supply chain's profit and increase the emission reduction effort when compared with the delay-in-payment and full cooperation modes.

As discussed in Section 1, the SMEs in the supply chain suffer from financing constraints and emission reduction regulation. Therefore, the SMEs simultaneously make decisions on operations, financing, and emission reduction. The existing literature lacks the study of capital-constrained supply chains from the perspective of carbon emission reduction. Besides the literature in Section 2.3, our study further fills this gap. Unlike in previous work $[38,39]$, we concentrate on bank credit financing. The second contribution in this study is the innovation of coordinating mechanism. We therefore propose a revenue sharing contract with a function form that can coordinate the low carbon supply chain and result in improved Pareto. Moreover, we provide several sensitive analyses of parameters on profits and decisionmaking processes. A high carbon price leads to a high reduction of emission in the supply chain. Thus, more quota savings bring considerable profit to the supply chain.

\section{Model}

3.1. Model Description and Assumptions. This study considers a single-period product market, where the distribution channel consists of a manufacturer and a retailer. The manufacturer acts as a monopolist firm that controls the manufacturing, whereas the retailer is an SME with no wealth endowment. The demand in the retailer market is random and is not realized until the end of the period.

The manufacturer announces a wholesale price for the retailer at time zero. The retailer must decide the order quantity and render full payment for the purchase. The capital-constrained retailer must loan from a bank.

The main assumptions in our model are as follows.

(1) The retail price is normalized to 1 without loss of generality. The product is perishable. Thus, it has no salvage value at the end of the period.

(2) Consumers hold the same reservation price for the product.

(3) In the retailer market, the demand distribution function is continuous with a positive probability density and has a finite mean.

(4) The manufacturer and the retailer have no fixed costs. The manufacturer has a constant marginal production cost. The retailer incurs the costs of the wholesale price and the interest rate of the bank credit.
(5) The retailer has limited liability, which implies that it repays the principal and interest to the bank if it realizes that revenue exceeds the sum of the principal and interest. Otherwise, the retailer only has to repay its total realized revenue and is in arrears with the remainder of the loan.

(6) The manufacturer has adequate capital for the production and emission reduction.

(7) The manufacturer is given an amount of initial carbon dioxide emission at time zero. The manufacturer must buy the right to emit if it emits more than its emission quota. On the contrary, the manufacturer can sell the emission permits if it emits fewer than its quota. The emission reduction cost is a function of the amount of carbon emission reduction per unit product. Moreover, the first and second derivatives of the function are greater than zero.

(8) The participants of the game are assumed to be rational and risk-neutral and have complete information. The banking market is perfectly competitive.

3.2. Notations. This study defines the following notations to formulate the problems.

$D$ : demand in the retail market

$F(D)$ : distribution function of $D$

$f(D)$ : probability density function of $D$

$\bar{F}(D)$ : cumulative distribution function of $D, \bar{F}(D)=$ $1-F(D)$

$w$ : wholesale price

Q: order quantity of the retailer/production quantity of the manufacturer

$r$ : interest rate of banks

$\pi$ : expected profits

$c$ : constant marginal production cost

$P_{c}$ : price of unit carbon emission permit in the carbon trading market

$e$ : initial amount of carbon emission per unit product by the manufacturer

$E_{c}$ : emission quota of the manufacturer

$\triangle e$ : amount of carbon emission reduction per unit product by the manufacturer

$\alpha$ : emission reduction investment coefficient

$M, R, S$ : used as superscripts to represent manufacturer, retailer, and supply chain, respectively

$d, t, v$ : used as subscripts to denote the decentralized distribution channel, the centralized distribution channel, and the revenue sharing function contract, respectively; for example, $\pi_{d}^{R}$ denotes the expected profits of the retailer in the decentralized distribution channel

*: superscript to represent an optimal choice; for example, $Q_{t}^{*}$ represents the optimal choice of retailer's order quantity in the centralized distribution channel

$H(\bullet)$ : Hessian matrix of a function 
$T(Q)$ : revenue sharing function

$N$ : constant term used in $T(Q)$

3.3. Decision-Making Process. This subsection considers a decentralized distribution channel. The manufacturer is assumed as a Stackelberg leader. At time zero, the manufacturer chooses a wholesale price $w_{d}$ first, and the retailer chooses an order quantity $Q_{d}$. Banks finally announce an interest rate $r_{d}$ after observing $w_{d}$ and $Q_{d}$.

We process the decision-making process backward to gain the equilibrium in the bank market and the distribution channel. In the bank market, a bank lends $w_{d} Q_{d}$ to the retailer. At the end of the period, the retailer achieves revenue $\min \left\{D, Q_{d}\right\}$ and uses it to pay the debt, $w Q_{d}\left(1+r_{d}\right)$. Given that the retailer has limited liability, its expected payment to the bank is $E \min \left\{\min \left\{D, Q_{d}\right\}, w_{d} Q_{d}\left(1+r_{d}\right)\right\}$. In a perfectly competitive bank market, the equilibrium condition in which the bank generates zero expected profits is as follows:

$$
E \min \left\{\min \left\{D, Q_{d}\right\}, w_{d} Q_{d}\left(1+r_{d}^{*}\right)\right\}=w_{d} Q_{d} .
$$

The expected profits of the retailer are

$$
\pi_{d}^{R}=E\left(\min \left\{D, Q_{d}\right\}-w_{d} Q_{d}\left(1+r_{d}^{*}\right)\right)^{+},
$$

where $x^{+}$equals $x$ when $x>0$ and equals 0 otherwise. Thus, the retailer's problem can be written as

$$
\begin{array}{ll}
\max _{Q_{d} \geq 0} & E\left(\min \left\{D, Q_{d}\right\}-w_{d} Q_{d}\left(1+r_{d}^{*}\right)\right)^{+} \\
\text {s.t. } & E \min \left\{\min \left\{D, Q_{d}\right\}, w_{d} Q_{d}\left(1+r_{d}^{*}\right)\right\}=w_{d} Q_{d} .
\end{array}
$$

Lemma 1 (see [18]). If $\left(1+r_{d}^{*}\right) w_{d}<1$, then the retailer's decision-making problem in (3a) and (3b) is equivalent to the standard newsvendor problem without a capital constraint, which is similar to that in

$$
\max _{Q_{d} \geq 0} E \min \left\{D, Q_{d}\right\}-w_{d} Q_{d} .
$$

From Lemma 1, we know that the capital-constrained channel is equivalent to the usual channel without a capital constraint if the bank market is perfectly competitive. Thus, the retailer with limited liability may opt for an order quantity that is the same as that when its own funds have been sufficient. Thus, for a given wholesale price $w_{d}$, the retailer's optimal order quantity $Q_{d}\left(w_{d}\right)$ is determined by the equation as follows [18]:

$$
w_{d}=\bar{F}\left(Q_{d}\right) .
$$

The expected profits of the manufacturer are

$$
\pi_{d}^{M}=\left(w_{d}-c\right) Q_{d}+P_{c}\left[E_{c}-\left(e-\Delta e_{d}\right) Q_{d}\right]-\frac{1}{2} \alpha \Delta e_{d}^{2}
$$

where $w_{d}=\bar{F}\left(Q_{d}\right)$. From (5), the choice of $w_{d}$ is equivalent to choosing $Q_{d}$ for the manufacturer. In other words, (6) can be rewritten as

$$
\begin{aligned}
\pi_{d}^{M}= & \left(\bar{F}\left(Q_{d}\right)-c\right) Q_{d}+P_{c}\left[E_{c}-\left(e-\Delta e_{d}\right) Q_{d}\right] \\
& -\frac{1}{2} \alpha \Delta e_{d}^{2} .
\end{aligned}
$$

To maximize the manufacturer's profit, we obtain the subgame perfect equilibrium as the following proposition.

Proposition 2. In a decentralized distribution channel with the capital-constrained retailer, if $2 f\left(Q_{d}\right)+Q_{d} f^{\prime}\left(Q_{d}\right)>P_{c}^{2} / \alpha$, then the equilibrium conditions are as follows:

(1) the retailer's best strategy is to choose order quantity $Q_{d}=Q_{d}^{*}$, where $Q_{d}^{*}$ is uniquely determined by equality

$$
\bar{F}\left(Q_{d}^{*}\right)-Q_{d}^{*} f\left(Q_{d}^{*}\right)+\frac{P_{c}^{2}}{\alpha} Q_{d}^{*}=c+P_{c} e ;
$$

(2) the wholesale price chosen by the manufacturer is $w_{d}^{*}=$ $\bar{F}\left(Q_{d}^{*}\right)$, and the amount of emission reduction per unit product is $\triangle e_{d}^{*}=\left(P_{c} / \alpha\right) Q_{d}^{*}$;

(3) the interest rate of the bank is uniquely given by $E \min \left\{\min \left\{D, Q_{d}^{*}\right\}, w_{d}^{*} Q_{d}^{*}\left(1+r_{d}^{*}\right)\right\}=w_{d}^{*} Q_{d}^{*}$.

Proof. In Proposition 2, condition (3) and the former part of condition (2) are derived from (1) and (5), respectively. We prove the other conditions in the following discussions. From (7), by taking the first-order partial derivatives of $\pi_{d}^{M}$ with respect to $\Delta e_{d}$ and $Q_{d}$, the equalities are as follows:

$$
\begin{aligned}
\frac{\partial \pi_{d}^{M}}{\partial \Delta e_{d}} & =P_{c} Q_{d}-\alpha \Delta e_{d}, \\
\frac{\partial \pi_{d}^{M}}{\partial Q_{d}} & =\bar{F}\left(Q_{d}\right)-Q_{d} f\left(Q_{d}\right)-P_{c}\left(e-\Delta e_{d}\right)-c .
\end{aligned}
$$

Thus, the Hessian matrix of $\pi_{d}^{M}$ is

$$
H\left(\pi_{d}^{M}\right)=\left[\begin{array}{cc}
-\alpha & P_{c} \\
P_{c} & -2 f\left(Q_{d}\right)-Q_{d} f^{\prime}\left(Q_{d}\right)
\end{array}\right] .
$$

If $\alpha\left[2 f\left(Q_{d}\right)+Q_{d} f^{\prime}\left(Q_{d}\right)\right]-P_{c}^{2}>0$, then $H\left(\pi_{d}^{M}\right)$ is a negative definite. Moreover, from the first-order condition, we can easily obtain condition (1) and the left part of condition (2) of the proposition.

\section{Contract to Coordinate the Channel}

4.1. Production Quantity in the Centralized Distribution Channel. In the centralized distribution channel, the expected profits of the supply chain are

$$
\pi_{t}^{S}=\pi_{t}^{M}+\pi_{t}^{R}=\pi_{d}^{M}+\pi_{d}^{R} .
$$

The centralized problem can be written as

$$
\begin{gathered}
\max _{Q_{t} \geq 0} E \min \left\{D, Q_{t}\right\}-c Q_{t}+P_{c}\left[E_{c}-\left(e-\Delta e_{t}\right) Q_{t}\right] \\
-\frac{1}{2} \alpha \Delta e_{t}^{2}
\end{gathered}
$$

s.t. $E \min \left\{\min \left\{D, Q_{t}\right\}, w_{t} Q_{t}\left(1+r_{t}\right)\right\}=w_{t} Q_{t}$.

Proposition 3. In the centralized channel with the capitalconstrained retailer, if $f\left(Q_{t}\right)>P_{c}^{2} / \alpha$, the optimal decisionmaking processes are achieved with the following conditions: 
(1) the supply chain's best strategy is to choose the production quantity $Q_{t}^{*}$, where $Q_{t}^{*}$ is uniquely determined by the equality

$$
\bar{F}\left(Q_{t}^{*}\right)+\frac{P_{c}^{2}}{\alpha} Q_{t}^{*}=c+P_{c} e
$$

(2) the amount of emission reduction per unit product is $\triangle e_{t}^{*}=\left(P_{c} / \alpha\right) Q_{t}^{*}$;

(3) for a given wholesale price $w_{t}$, the interest rate of the bank is uniquely given by $E \min \left\{\min \left\{D, Q_{t}^{*}\right\}, w_{t} Q_{t}^{*}\left(1+r_{t}^{*}\right)\right\}=$ $w_{t} Q_{t}^{*}$.

Proof. According to the proof process of Lemma 1,

$$
\begin{aligned}
\pi_{t}^{S}= & \int_{0}^{Q_{t}} \operatorname{DdF}(D)+\int_{Q_{t}}^{\infty} Q_{t} d F(D)-c Q_{t} \\
& +P_{c}\left[E_{c}-\left(e-\triangle e_{t}\right) Q_{t}\right]-\frac{1}{2} \alpha \Delta e_{t}^{2} .
\end{aligned}
$$

Taking the first-order partial derivatives of $\pi_{t}^{S}$ with respect to $\triangle e_{t}$ and $Q_{t}$, the equalities are as follows:

$$
\begin{aligned}
\frac{\partial \pi_{t}^{S}}{\partial \Delta e_{t}} & =P_{c} Q_{t}-\alpha \Delta e_{t}, \\
\frac{\partial \pi_{t}^{S}}{\partial Q_{t}} & =\bar{F}\left(Q_{t}\right)-P_{c}\left(e-\Delta e_{t}\right)-c .
\end{aligned}
$$

Thus, the Hessian matrix of $\pi_{t}^{S}$ is as follows:

$$
H\left(\pi_{t}^{S}\right)=\left[\begin{array}{cc}
-\alpha & P_{c} \\
P_{c} & -f\left(Q_{t}\right)
\end{array}\right] .
$$

If $\alpha f\left(Q_{t}\right)-P_{c}^{2}>0$, then $H\left(\pi_{t}^{S}\right)$ is a negative definite. We obtain conditions (1) and (2) of the proposition according to the first-order condition. Condition (3) can be derived from (1) directly. These conditions prove Proposition 3.

4.2. Coordination with a Revenue Sharing Function. This subsection uses a special revenue sharing contract, the function scheme, to coordinate the channel. In the contract, the wholesale price the manufacturer announces does not exceed the cost per unit product. Thus, the retail revenue is divided into two parts. The first part with the quantity of $T\left(Q_{v}\right)$ is given to the manufacturer, whereas the remaining part is kept by the retailer. We suppose $T\left(Q_{v}\right) \leq E \min \left\{D, Q_{v}\right\}$. Thus, the retailer's problem can be written as

$$
\begin{array}{ll}
\max _{Q_{v} \geq 0} & E\left(\min \left\{D, Q_{v}\right\}-T\left(Q_{v}\right)-w_{v} Q_{v}\left(1+r_{v}\right)\right)^{+} \\
\text {s.t. } & E \min \left\{\min \left\{D, Q_{v}\right\}-T\left(Q_{v}\right), w_{v} Q_{v}\left(1+r_{v}\right)\right\} \\
& =w_{v} Q_{v} .
\end{array}
$$

The manufacturer's profit becomes

$$
\begin{aligned}
\pi_{v}^{M}= & \left(w_{v}-c\right) Q_{v}+T\left(Q_{v}\right)+P_{c}\left[E_{c}-\left(e-\Delta e_{v}\right) Q_{v}\right] \\
& -\frac{1}{2} \alpha \Delta e_{v}^{2} .
\end{aligned}
$$

Proposition 4. Considering a revenue sharing function contract, a function with the form of

$$
T\left(Q_{v}\right)=-\frac{P_{c}^{2} Q_{v}{ }^{2}}{2 \alpha}+\left(c+P_{c} e-w_{v}\right) Q_{v}+N
$$

can coordinate the channel, where $N$ is a constant term to achieve $T\left(Q_{v}\right) \leq E \min \left\{D, Q_{v}\right\}$.

Proof. Suppose $Q_{v}-T\left(Q_{v}\right)>w_{v} Q_{v}\left(1+r_{v}\right)$; (17b) can be written as

$$
\begin{aligned}
w_{v} Q_{v}= & E \min \left\{\mathrm{D}-T\left(Q_{v}\right), w_{v} Q_{v}\left(1+r_{v}\right)\right\} \\
= & \int_{0}^{T\left(Q_{v}\right)+w_{v} Q_{v}\left(1+r_{v}\right)}\left(D-T\left(Q_{v}\right)\right) d F(D) \\
& +\int_{T\left(Q_{v}\right)+w_{v} Q_{v}\left(1+r_{v}\right)}^{\infty} w_{v} Q_{v}\left(1+r_{v}\right) d F(D) .
\end{aligned}
$$

Thus, we have

$$
\begin{aligned}
& \int_{T\left(Q_{v}\right)+w_{v} Q_{v}\left(1+r_{v}\right)}^{\infty} w_{v} Q_{v}\left(1+r_{v}\right) d F(D) \\
& \quad=w_{v} Q_{v}-\int_{0}^{T\left(Q_{v}\right)+w_{v} Q_{v}\left(1+r_{v}\right)}\left(D-T\left(Q_{v}\right)\right) d F(D) .
\end{aligned}
$$

Thus, the profit function of the retailer can be rewritten as

$$
\begin{aligned}
\pi_{v}^{R} & =\int_{T\left(Q_{v}\right)+w_{v} Q_{v}\left(1+r_{v}\right)}^{Q_{v}} \operatorname{DdF}(D)+\int_{Q_{v}}^{\infty} Q_{v} d F(D) \\
& -\int_{T\left(Q_{v}\right)+w_{v} Q_{v}\left(1+r_{v}\right)}^{\infty}\left(T\left(Q_{v}\right)\right. \\
& \left.+w_{v} Q_{v}\left(1+r_{v}\right)\right) d F(D) \\
& =\int_{T\left(Q_{v}\right)+w_{v} Q_{v}\left(1+r_{v}\right)}^{Q_{v}} D d F(D)+\int_{Q_{v}}^{\infty} Q_{v} d F(D) \\
& -\int_{T\left(Q_{v}\right)+w_{v} Q_{v}\left(1+r_{v}\right)}^{\infty} T\left(Q_{v}\right) d F(D)-w_{v} Q_{v} \\
& +\int_{0}^{T\left(Q_{v}\right)+w_{v} Q_{v}\left(1+r_{v}\right)}\left(D-T\left(Q_{v}\right)\right) d F(D) \\
& =\int_{0}^{Q_{v}} D d F(D)+\int_{Q_{v}}^{\infty} Q_{v} d F(D)-T\left(Q_{v}\right)-w_{v} Q_{v} .
\end{aligned}
$$

Differentiating $\pi_{v}^{R}$ with respect to $Q_{v}$ and collecting terms, we have $d \pi_{v}^{R} / d Q_{v}=\bar{F}\left(Q_{v}\right)-d T\left(Q_{v}\right) / d Q_{v}-w_{v}$. The retailer's optimal order quantity, $Q_{v}^{*}$, satisfies the first-order condition

$$
\bar{F}\left(Q_{v}^{*}\right)=w_{v}+\frac{d T\left(Q_{v}^{*}\right)}{d Q_{v}^{*}} .
$$

Moreover,

$$
\left.\frac{d^{2} \pi_{v}^{R}}{d Q_{v}{ }^{2}}\right|_{Q_{v}=Q_{v}^{*}}=-f\left(Q_{v}^{*}\right)-\left.\frac{d^{2} T\left(Q_{v}\right)}{d Q_{v}^{2}}\right|_{Q_{v}=Q_{v}^{*}}<0
$$

from the second-order condition. 
If the revenue sharing function contract coordinates the supply chain, then we have $Q_{v}^{*}=Q_{t}^{*}$. Substituting (23) into (13), we obtain $d T\left(Q_{v}\right) / d Q_{v}=-\left(P_{c}^{2} / \alpha\right) Q_{v}+c+$ $P_{c} e-w_{v}$. Therefore, (19) is satisfied. Moreover, according to (24) and $Q_{v}^{*}=Q_{t}^{*}$ gained above, we have $-f\left(Q_{v}^{*}\right)-$ $\left.\left(d^{2} T\left(Q_{v}\right) / d Q_{v}^{2}\right)\right|_{Q_{v}=Q_{v}^{*}}<0$. Given that $d^{2} T\left(Q_{v}\right) / d Q_{v}^{2}=$ $-P_{c}^{2} / \alpha$, we obtain $f\left(Q_{t}^{*}\right)>P_{c}^{2} / \alpha$, which insures that the optimal quantity $Q_{t}^{*}$ exists according to Proposition 3. Thus, we have proven Proposition 4.

Remark 5. Letting $w_{v}=0$, we have $T\left(Q_{v}\right)=-P_{c}^{2} Q_{v}^{2} / 2 \alpha+$ $\left(c+P_{c} e\right) Q_{v}+N$. The revenue sharing contract with a function form becomes a special case that likes the quantity discount contract. Unlike the traditional quantity discount contract, $T\left(Q_{\nu}\right)$ is a function form, and the manufacturer cannot obtain the payment for the products until the retailer has achieved the sales income. Therefore, $T\left(Q_{v}\right)$ is a hybrid contract of revenue sharing and quantity discount. This setup is beneficial for the retailer that is an SME because it does not need to pay the money to obtain the products. Thus, the retailer also does not need to load from the banks.

Proposition 6. In the revenue sharing function contract, the manufacturer's optimal carbon emission reduction per unit product is $\triangle e_{v}^{*}=\left(P_{c} / \alpha\right) Q_{v}^{*}$.

Proof. From (18), we have

$$
\frac{d \pi_{v}^{M}}{d \triangle e_{v}}=P_{c} Q_{v}^{*}-\alpha \Delta e_{v}
$$

According to the first-order condition and $d^{2} \pi_{v}^{M} / d \triangle e_{v}^{2}=$ $-\alpha<0$, we obtain $\triangle e_{v}^{*}=\left(P_{c} / \alpha\right) Q_{v}^{*}$.

Remark 7. Proposition 4 shows that $T\left(Q_{v}\right)$ is a parabola that moves downward, and its highest point is achieved when $Q_{v}=\alpha\left(c-w_{v}+P_{c} e\right) / P_{c}^{2}$. However, we obtain $\Delta e_{v}^{*}=\left(P_{c} / \alpha\right) Q_{v}^{*}$ from Proposition 6 because the emission reduction amount cannot surpass the initial amount of carbon emission per unit product. Thus, we have $Q_{v}^{*}<\alpha e / P_{c}$. In the revenue sharing function contract, we assume that the wholesale price does not exceed the marginal production cost. Thus, if $\alpha(c-$ $\left.w_{v}\right) / P_{c}^{2}>0$, then $Q_{v}^{*}<\alpha e / P_{c}+\alpha\left(c-w_{v}\right) / P_{c}^{2}$, i.e., $Q_{v}^{*}<$ $\alpha\left(c-w_{v}+P_{c} e\right) / P_{c}^{2}$. This correspondence means that the curve of $T\left(Q_{v}\right)$ can only work at the left part because of the choice of $Q_{v}^{*}$. Figure 1 shows that the solid line describes $T\left(Q_{v}\right)$. The monotonicity of $T\left(Q_{v}\right)$ matches the actual situation. The retailer must share more revenues to the manufacturer with the increase of order quantity.

4.3. Model Analysis. This subsection compares the decisionmaking processes of the decentralized and centralized channels, which include emission reduction investments, order quantities, and carbon emissions.

Corollary 8. In the supply chain, the manufacturer's emission reductions per unit product are linearly proportional to the

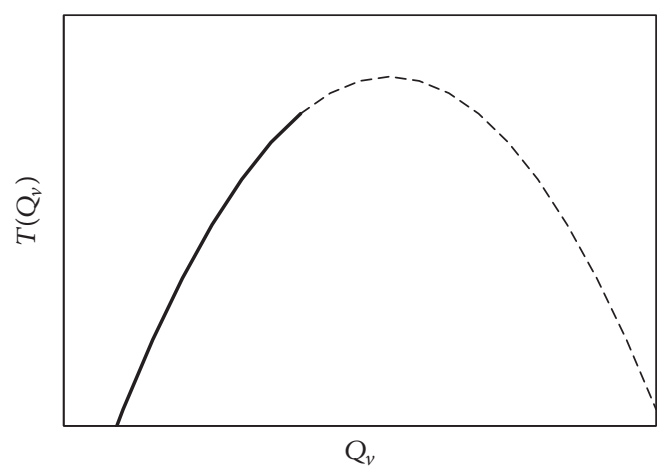

FIgURE 1: Curve of $T\left(Q_{v}\right)$.

order/production quantity, regardless of the centralized distribution channel, the decentralized channel, or the revenue sharing function contract. Moreover, the proportional coefficient is $P_{c} / \alpha$.

Corollary 8 reflects the decision-making process of low carbon investment, which only relies on order/production quantity regardless of the channel. The manufacturer is the monopolist in the channel, and the low carbon investment only appears in the manufacturer's revenue function. The retailer influences the low carbon investment by the order quantity indirectly.

Proposition 9. Suppose that the optimal order quantities in the decentralized and the centralized distribution channels are $Q_{d}^{*}$ and $Q_{t}^{*}$, respectively. They satisfy $Q_{d}^{*}, Q_{t}^{*} \in\left[Q_{1}, Q_{2}\right] . \forall Q \in$ $\left[Q_{1}, Q_{2}\right]$, if $f(Q)>P_{c}^{2} / \alpha$, then $Q_{d}^{*}<Q_{t}^{*}$.

Proof. Denoting $G(Q) \equiv \bar{F}(Q)+\left(P_{c}^{2} / \alpha\right) Q, d G(Q) / d Q=$ $-f(Q)+P_{c}^{2} / \alpha$. If $f(Q)>P_{c}^{2} / \alpha$, then $d G(Q) / d Q<0$ and $G(Q)$ monotonically decreases in $Q$. Propositions 2 and 3 reveal that $G\left(Q_{d}^{*}\right)-G\left(Q_{t}^{*}\right)=Q_{d}^{*} f\left(Q_{d}^{*}\right)>0$ because $Q_{d}^{*}>0$ and $f\left(Q_{d}^{*}\right)>0$. Thus, according to the monotonicity of $G(Q)$, $Q_{d}^{*}<Q_{t}^{*}$.

If $f(Q)>P_{c}^{2} / \alpha$, then the cost of emission reduction is relatively high and the carbon price is relatively low. That is, the manufacturer cannot gain more benefits from a large order quantity in the decentralized distribution channel. From Corollary 8, a large order quantity means large emission reductions per unit product. The manufacturer can harvest little income from $P_{c} \triangle e Q$ with the heavy emission reduction investment of $(1 / 2) \alpha \Delta e^{2}$. In the centralized distribution channel, the profits from the retail market can compensate the cost of emission reduction. Thus, production quantity is more than that in the decentralized channel.

$C(Q)$ denotes the carbon emissions to manufacture $Q$ products in the supply chain, while $C\left(Q_{d}^{*}\right)$ and $C\left(Q_{t}^{*}\right)$ represent the carbon emissions for optimal decision-making in the decentralized and centralized distribution channels, respectively.

Corollary 10. If $Q_{d}^{*}, Q_{t}^{*} \in\left[Q_{1}, Q_{2}\right]$ is satisfied and $\forall Q \in$ $\left[Q_{1}, Q_{2}\right], f(Q)>P_{c}^{2} / \alpha$. Moreover, if $Q_{2}<\alpha e / 2 P_{c}$ is satisfied, 
then $C\left(Q_{d}^{*}\right)<C\left(Q_{t}^{*}\right)$; if $\alpha e / 2 P_{c}<Q_{1}<Q_{2}<\alpha e / P_{c}$ is satisfied, then $C\left(Q_{d}^{*}\right)>C\left(Q_{t}^{*}\right)$.

Proof. Given that the emission reduction amount cannot exceed the initial carbon emissions, we obtain $Q_{2}<\alpha e / P_{c}$ according to Proposition 3. Moreover, from Corollary 8, $C(Q)=(e-\Delta e) Q=\left(e-\left(P_{c} / \alpha\right) Q\right) Q$. Then, $d C(Q) / d Q=$ $e-\left(2 P_{c} / \alpha\right) Q$. Thus, if $Q<\alpha e / 2 P_{c}$, then function $C(Q)$ is monotonically increasing in $Q$. If $Q>\alpha e / 2 P_{c}$, then function $C(Q)$ is monotonically decreasing in $Q$. Therefore, according to Proposition 9, we can easily gain Corollary 10 .

The channel in which the quantity of carbon emissions is greater is uncertain and depends on the size relationships between $f(Q)$ and $P_{c}^{2} / \alpha$ and between $Q$ and $\alpha e / 2 P_{c}$, where $Q$ represents $Q_{d}^{*}$ and $Q_{t}^{*}$. If neither of the conditions in Corollary 10 is satisfied, then we can compare the carbon emissions of two channels by means of computational experiments.

\section{Numerical Examples}

This section presents the conduct of a set of numerical computations to study the solutions in the decentralized distribution channel, the centralized channel, and the revenue sharing function contract. To perform these experiments, we use an exponential distribution with a mean value of 100 to model demand uncertainty. The other parameters in the model are set to $c=0.2, e=3, E_{c}=320, \alpha=10$, and $P_{c}=0.1$.

5.1. Illustrating Example of the Contract. In the decentralized channel, the optimal order quantity is $Q_{d}^{*}=34.35$, and the optimal wholesale price is 0.71 . The profits of the manufacturer and the retailer are 39.78 and 4.71, respectively. Therefore, the total profit of the supply chain is 44.49 . In the centralized channel, the order quantity is $Q_{t}^{*}=88.88$, and the supply chain's total profit is 50.39 . Thus, the supply chain gains 5.9 more profit than the decentralized channel.

From channel coordination, the manufacturer and the retailer can gain more profit as long as the constant term, $N$, is within a mutually beneficial range, which is called the Pareto zone. As shown in Figure 2, when $N$ is in the Pareto zone of $(7.78,13.69)$, the revenue sharing function contract achieves a win-win result.

Given that $f(Q)$ is monotonically decreasing in $Q>0$ for the exponential distribution, the numerical example verifies Proposition 9. We consider Corollary 10. $\alpha e / 2 P_{c}=150>$ $Q_{t}^{*}>Q_{d}^{*}, C\left(Q_{t}^{*}\right)=187.64$, and $C\left(Q_{d}^{*}\right)=91.25$ test part of Corollary 10 . This example shows that the carbon emissions in the decentralized channel are nearly half of those in the centralized channel.

To analyze Corollary 10 deeply, we study a set of numerical examples and choose a representative example (Table 1). We vary only one parameter involved in Corollary 10, e, through the interval $[1.608,2.400]$ with the step length of 0.008 . We omit some of the trend data to effectively illustrate the results. The data are divided into three parts. In the bottom part, the data meet the condition $Q_{2}<\alpha e / 2 P_{c}$ when $Q_{2}=Q_{t}^{*}$. The data of carbon emissions in the decentralized and the centralized channels are consistent

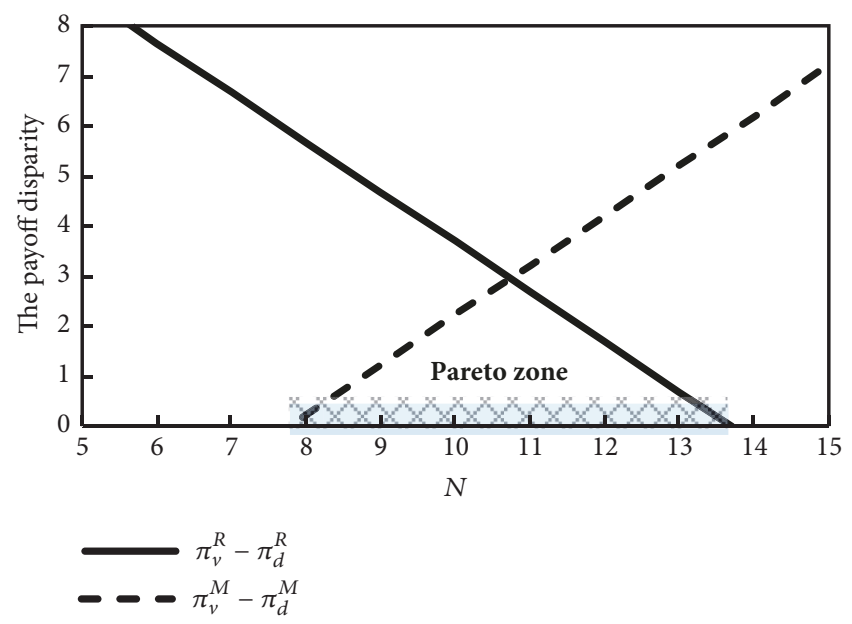

Figure 2: Pareto zone.

with the conclusion of Corollary 10, which is $C\left(Q_{d}^{*}\right)<C\left(Q_{t}^{*}\right)$. In the top and middle parts of the data, the order quantities meet neither $Q_{2}<\alpha e / 2 P_{c}$ nor $\alpha e / 2 P_{c}<Q_{1}<Q_{2}<\alpha e / P_{c}$. Moreover, the data in the top part show that $C\left(Q_{d}^{*}\right)>C\left(Q_{t}^{*}\right)$, whereas the data in the middle part show $C\left(Q_{d}^{*}\right)<C\left(Q_{t}^{*}\right)$.

5.2. Impact of Carbon Price Variability. Our next computational experiment measures the impact of carbon emission parameters on the performance in the model. We keep the emission reduction investment coefficient and the initial amount of carbon emission per unit product constant and vary the carbon price. Figure 3 plots the optimal order quantities in the feasible region of $P_{c}$. The choice of $\Delta e$ is above $e$ in our model when $P_{c} \geq 0.2$. In this example, the inequality is $Q_{d}^{*}<Q_{t}^{*}<\alpha e / 2 P_{c}$ for all $P_{c}<0.19$. With the increase in the price of carbon emission, the order quantity reduces in the decentralized and the centralized distribution channels.

As depicted by Figure 4, the amount of carbon emissions is decreased when the carbon price is increased (i.e., best decision-making option). Moreover, a high carbon price implies increased production cost, but the manufacturer can deal with this issue by lowering the production quantity, which then reduces carbon emissions.

The centralized channel brings more carbon emissions than the decentralized channel because the emissions that increased from the large production quantity are more than the reduction from the optimal choice of $\Delta e$. The gap between the centralized channel and the decentralized channel narrows when the carbon price rises. Therefore, maintaining the high carbon price in the market is beneficial for the emission reduction target of the government.

We study the supply chain's profit with the change of carbon price. Figure 5 shows that the profit of the supply chain is always higher in the centralized channel than that in the decentralized channel. In the decentralized channel, the profits increase as the carbon price grows. However, the profit in the centralized channel initially slightly decreases, and then it increases, which is similar to that in the decentralized channel. 


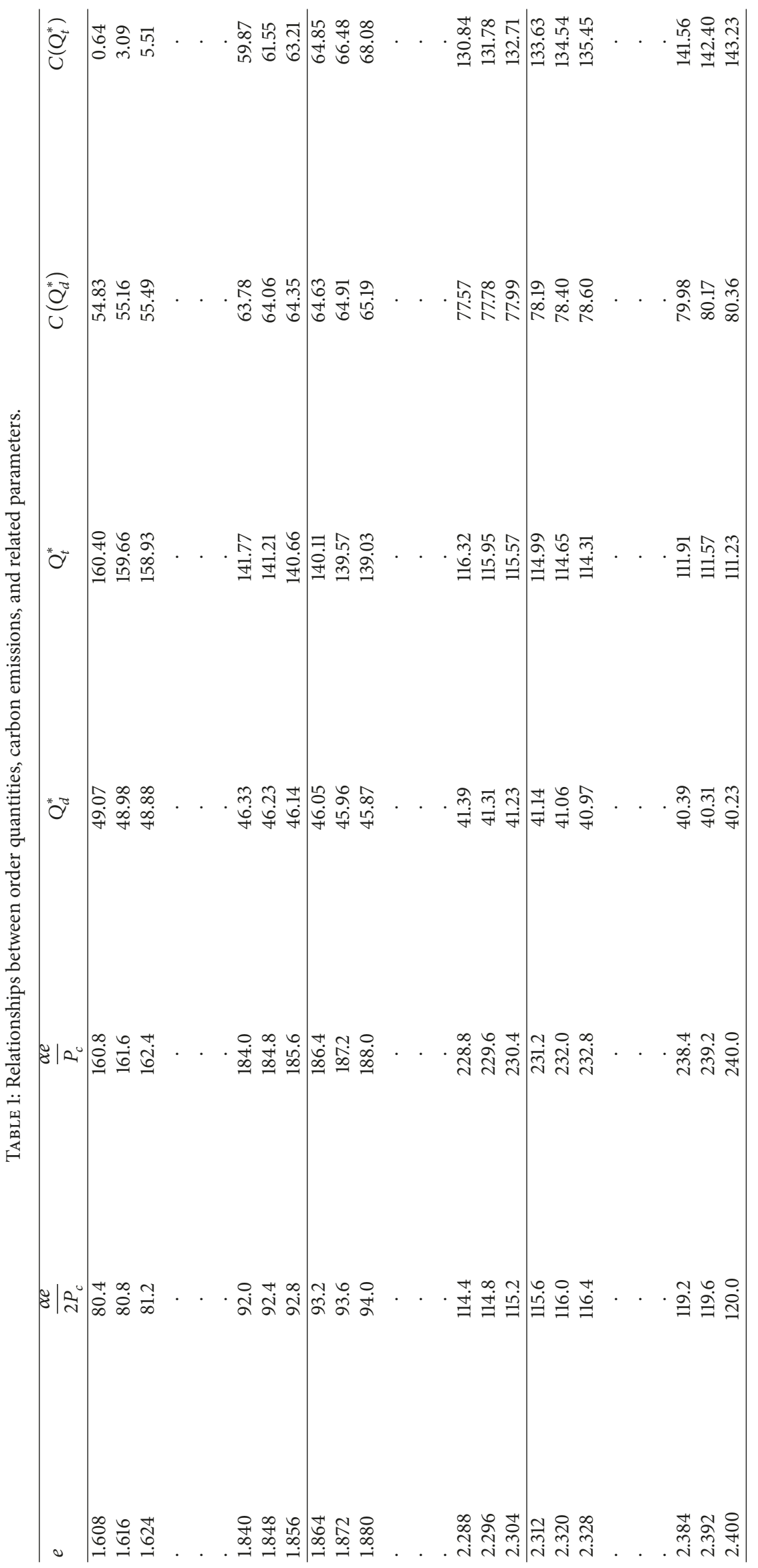




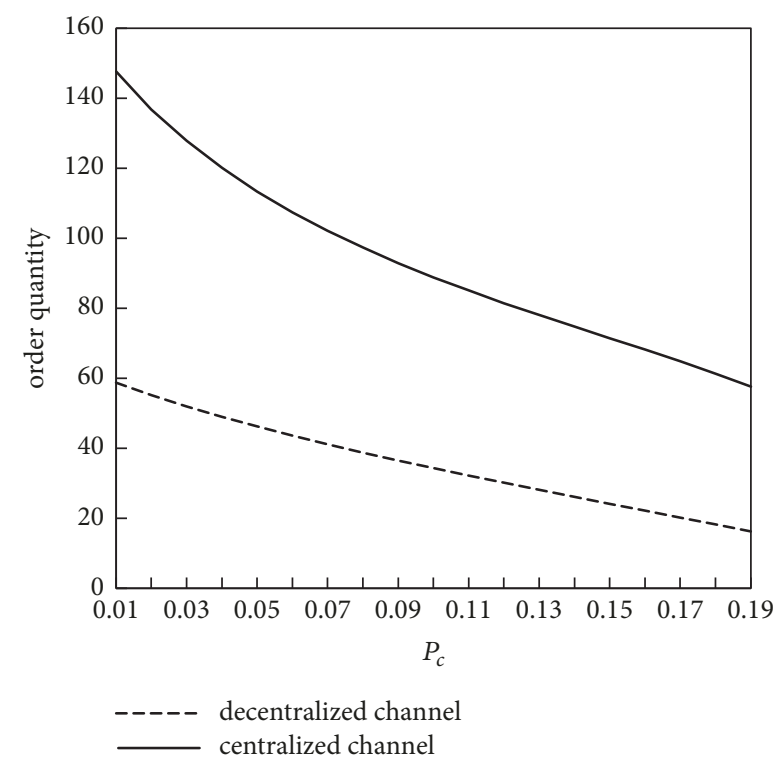

FIGURE 3: Order quantities under different carbon prices.

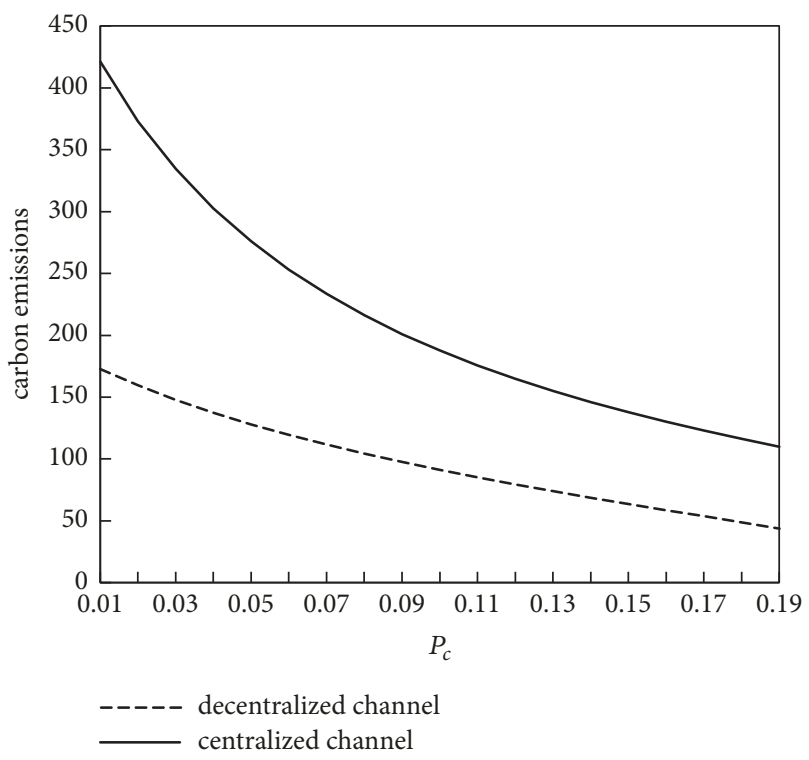

FIGURE 4: Carbon emissions under different carbon prices.

We analyze the reason for using the profit structure. As shown in Figure 6, when the carbon price is increased, the part of the carbon (i.e., income from the sale of some carbon emission quota) increases linearly. This scenario can be attributed to the order quantity reduction and the sale of the remainder of the quota. However, the part of the product in profits, which is the income only from the manufacturing and sale for the product, decreases like the curve of order quantity in Figure 3. It has a negative slope, and the absolute value of the slope becomes increasingly small with the increase of carbon price. Therefore, the sum of the above two parts indicates the shape of the profit curve in the centralized channel.

5.3. Impact of Cost Variability. In the last computational experiment, we vary the constant marginal production cost

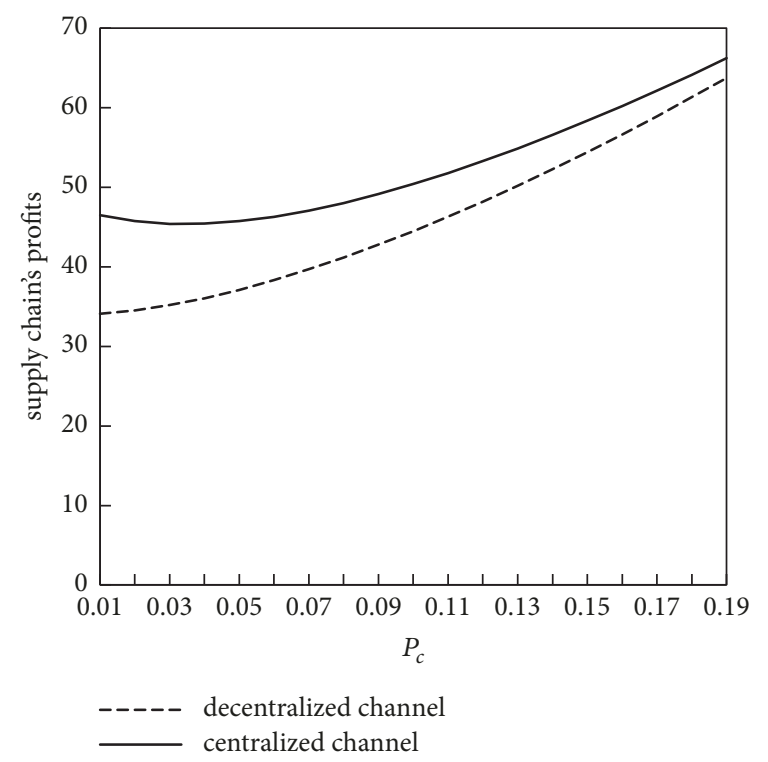

FIGURE 5: Supply chain's profits under different carbon prices.

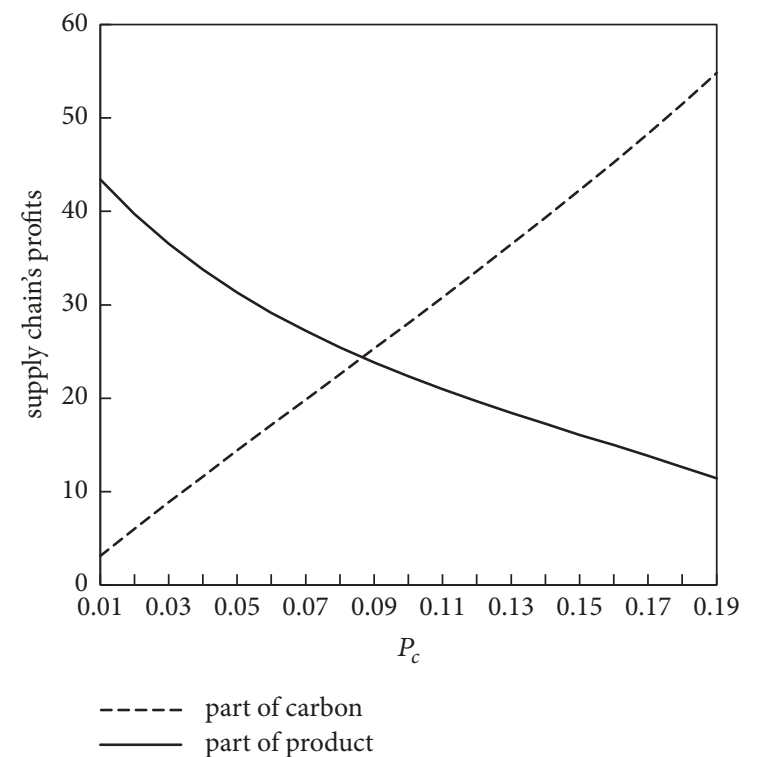

Figure 6: Profit structure under different carbon prices in the centralized channel.

within the interval $[0.1,1)$ and measure its impact on the performance of the model. Figure 7 shows that the order quantities decrease as the marginal production cost grows. When the marginal production cost is close to 0.7 , the order quantity reduces to 0 . Therefore, we omit the interval $(0.7,1)$ in Figure 7. The gap between two channels also decreases. In other words, the descent rate of order quantity is fast in the centralized channel. Moreover, the supply chain tends to stop production when the marginal production cost is close to the sale price. The supply chain chooses more order quantities in the centralized channel than that in the decentralized channel because it depends on $f(\bullet)$ and carbon emission parameters but not on the marginal production cost. 


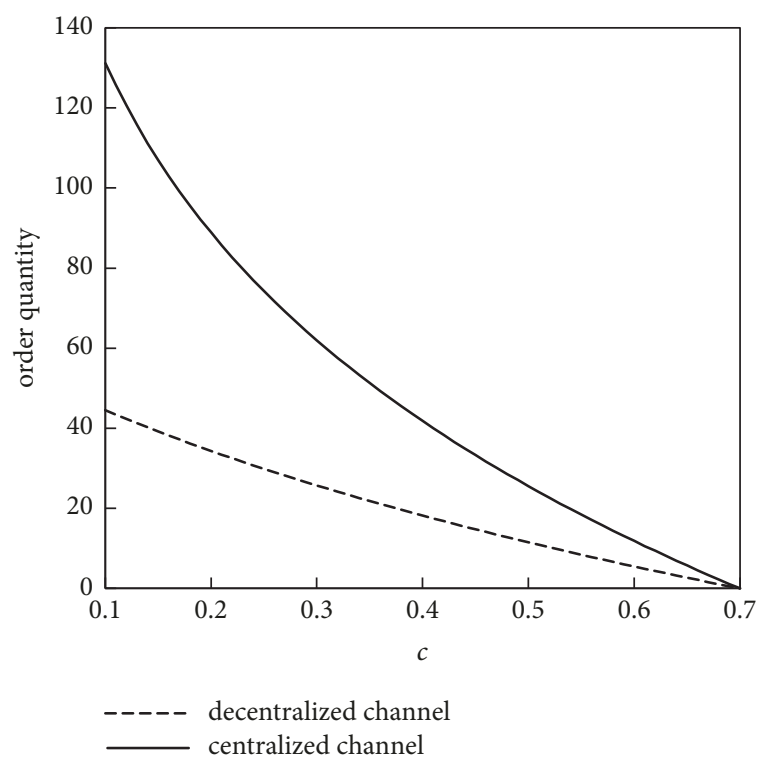

Figure 7: Order quantities under different marginal production costs.

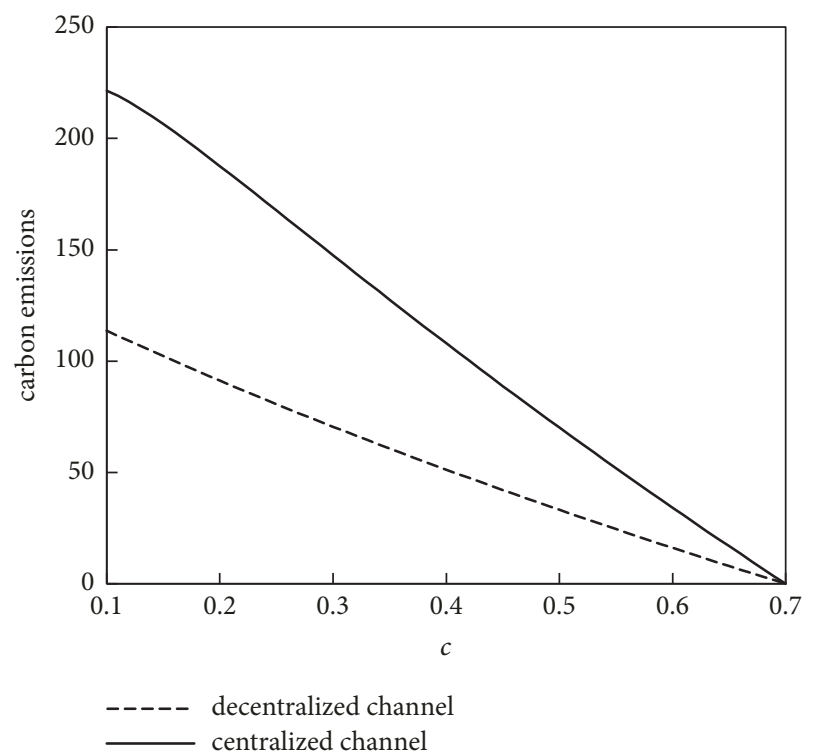

Figure 8: Carbon emissions under different marginal production costs.

As shown in Figures 8 and 9, although the curves of carbon emissions are straighter than the curves of supply chain's profits, their changing trends are nearly the same as the order quantities. When the order quantity reduces to 0 , the supply chain gains the profit (32) from the sales of the carbon quota. Moreover, we study the profit structure in the centralized channel. Figure 10 shows that our centralized model is always profitable from the sales of quota no matter how the production cost varies from 0.1 to 0.7 because, from the investment of emission reduction, the manufacturer has the quota surplus. With the increase of production cost, the order quantity reduces and causes emission reduction. Thus,

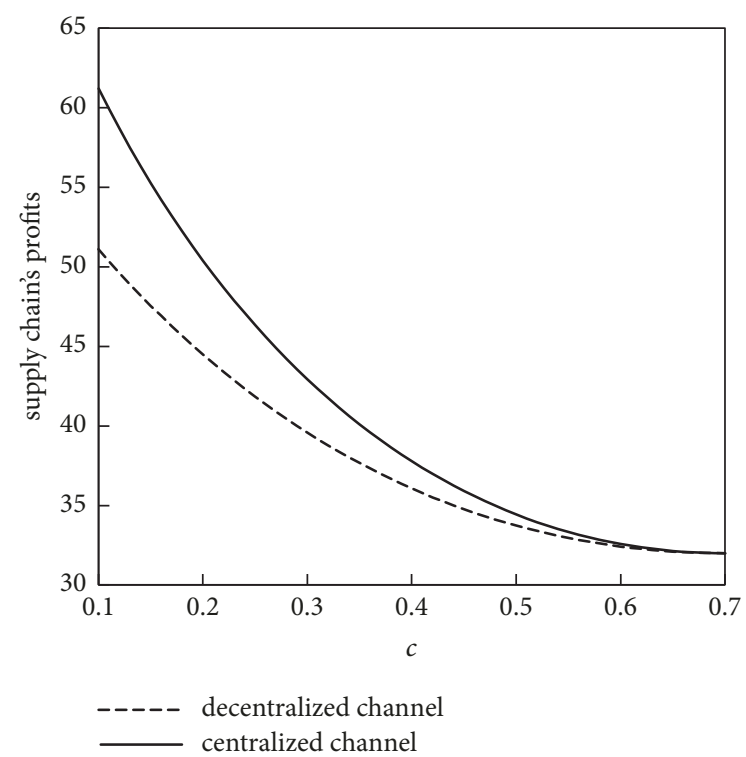

FIGURE 9: Supply chain's profits under different marginal production costs.

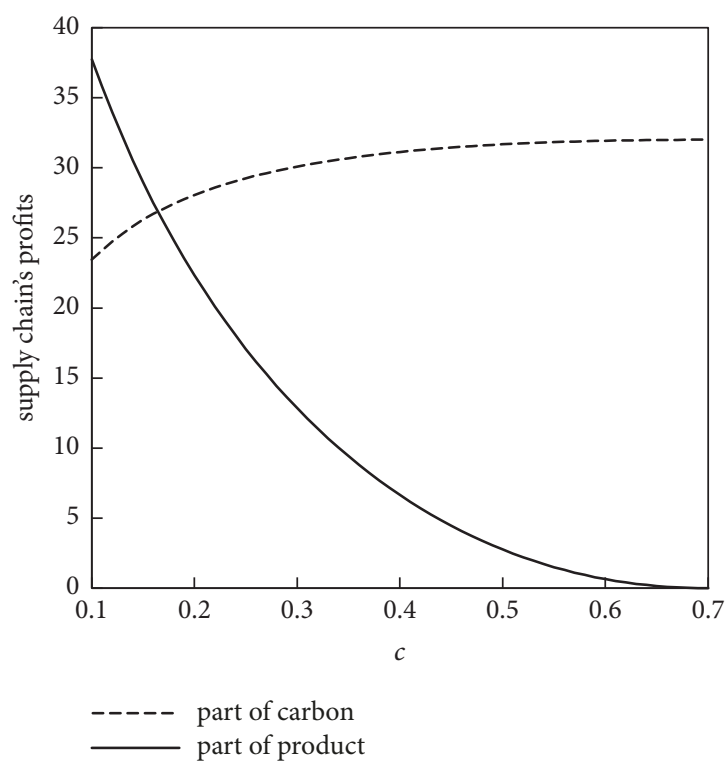

Figure 10: Profit structure under different marginal production costs in the centralized channel.

the part of carbon profits grows. However, from the view of the curve shapes, we find that the carbon profit curve is flatter than the product profit curve. They intersect near $c=0.1646$. Therefore, more order quantities lead to more emissions and the reduction of surplus quota but can gain more profit for product sales and induce more total profit.

\section{Conclusions}

This study considers a low carbon distribution channel where the retailer is capital-constrained. Given that the manufacturer is a monopolist, the retailer has to loan from a bank 
for product payment. With the assumptions of the retailer's limited liability and the perfect competition in the banking market, we found that capital constraints have no influence on the retailer's optimal order quantity. Other main results, which can provide useful managerial insights, are obtained as follows.

First, we investigate the decentralized distribution channel and the centralized distribution channel. After analyzing and comparing the optimal equilibrium solutions of both channels, we find that the manufacturer's decision on the carbon emission reductions per unit product is linearly proportional to the order quantity, regardless of the centralized distribution channel or the decentralized channel. This finding implies that, with the increase in the retailer's order quantity, the manufacturer can exert more effort to reduce emissions. The relatively high carbon price and the relatively low emission reduction investment coefficient can increase the manufacturer's effort. Moreover, we compare the order quantity and the total carbon emissions between the two channels. Within a specified interval of order quantities when the value of the probability density function of demand is above a threshold, the order quantity in the centralized channel is greater than that in the decentralized channel. If this interval satisfies some certain conditions, then we can identify in which channel it produces more carbon emissions. Thus, although the retailer orders more products in the centralized channel, the supply chain's total carbon emissions can be lesser than those in the decentralized channel in certain situations, and this phenomenon is beneficial to the supply chain and the environment.

Second, to achieve the highest efficiency of the overall supply chain, we design a coordination contract named as the revenue sharing function, in which we use a function form instead of the revenue share ratio. In our model, the revenue sharing function is quadratic with respect to order quantity and only takes the ascending section of the parabola, which moves downward. The contract renders a win-win result for the channel members when the constant term in the function is in the Pareto zone.

Finally, a set of numerical computations is implemented to verify our model and analyze the impacts of the carbon price and production cost. With the increase in production cost, the manufacturer tends to produce less or not produce at all. Thus, the profit is reduced and achieved mainly by the sale of emission quotas. However, the high carbon price can bring more profit to the supply chain if quota savings can compensate the reduced orders. This finding implies that the government's appropriate quota allocation and relatively high carbon price setting may benefit the environment and the supply chain efficiency.

This study assumes that the retailer has limited liability. However, in practice, the failure of loan repayment leads to bankruptcy. Extending this assumption will have an effect on supply chain decisions. Thus, one key research direction is to consider the bankruptcy costs. Second, only the retailer is constrained by capital in our model. Another possible extension is to consider the case where the manufacturer is also constrained by capital.

\section{Data Availability}

The data used to support the findings of this study are available from the corresponding author upon request.

\section{Disclosure}

The founding sponsors have no role in the design of the study, the writing of the manuscript, and the decision to publish the results.

\section{Conflicts of Interest}

The authors declare no conflicts of interest.

\section{Acknowledgments}

This research work was partially supported by the National Natural Science Foundation of China (11771322).

\section{References}

[1] S. Solomon, D. Qin, and M. Manning, "Technical summary," Climate Change 2007: The Physical Science Basis, Cambridge University Press, Cambridge, UK, 2007.

[2] X. Chen, S. Benjaafar, and A. Elomri, "The carbon-constrained EOQ," Operations Research Letters, vol. 41, no. 2, pp. 172-179, 2013.

[3] Y. Li, C. Wei, and X. Cai, "Optimal pricing and order policies with $\mathrm{B} 2 \mathrm{~B}$ product returns for fashion products," International Journal of Production Economics, vol. 135, no. 2, pp. 637-646, 2012.

[4] X. Chen, Z. Pang, and L. Pan, "Coordinating inventory control and pricing strategies for perishable products," Operations Research, vol. 62, no. 2, pp. 284-300, 2014.

[5] X. Liu, "Impacts of the global financial crisis on small and medium enterprises in the People's Republic of China," Asian Development Bank Institute, ADBI Working Papers, 2009, SSRN: https://ssrn.com/abstract=1627967.

[6] L. Zhao and A. Huchzermeier, "Operations-finance interface models: a literature review and framework," European Journal of Operational Research, vol. 244, no. 3, pp. 905-917, 2015.

[7] X. D. Xu and J. R. Birge, "Joint production and financing decisions: modeling and analysis," SSRN Electronic Journal, 2004, SSRN: http://ssrn.com/abtract=652562.

[8] P. Kouvelis and W. Zhao, "Financing the newsvendor: supplier vs. bank, and the structure of optimal trade credit contracts," Operations Research, vol. 60, no. 3, pp. 566-580, 2012.

[9] B. Jing and A. Seidmann, "Finance sourcing in a supply chain," Decision Support Systems, vol. 58, no. 1, pp. 15-20, 2014.

[10] Y. Feng, Y. Mu, B. Hu, and A. Kumar, "Commodity options purchasing and credit financing under capital constraint," International Journal of Production Economics, vol. 153, no. 1, pp. 230-237, 2014.

[11] J. Shi, R. Y. Fung, and J. Guo, "Optimal ordering and pricing policies for seasonal products: impacts of demand uncertainty and capital constraint," Discrete Dynamics in Nature and Society, vol. 2016, Article ID 1801658, 13 pages, 2016. 
[12] J. Shi, J. Guo, and R. Y. K. Fung, "Decision support system for purchasing management of seasonal products: a capitalconstrained retailer perspective," Expert Systems with Applications, vol. 80, pp. 171-182, 2017.

[13] N. Yan, C. Liu, Y. Liu, and B. Sun, "Effects of risk aversion and decision preference on equilibriums in supply chain finance incorporating bank credit with credit guarantee," Applied Stochastic Models in Business and Industry, vol. 33, no. 6, pp. 602-625, 2017.

[14] J. A. Buzacott and R. Q. Zhang, "Inventory management with asset-based financing," Management Science, vol. 50, no. 9, pp. 1274-1292, 2004.

[15] O. Boyabatli and L. B. Toktay, "Capacity investment in imperfect capital markets: the interaction of operational and financial decisions," Klinische Wochenschrift, 2007.

[16] D. Seifert, R. W. Seifert, and M. Protopappa-Sieke, "A review of trade credit literature: opportunities for research in operations," European Journal of Operational Research, vol. 231, no. 2, pp. 245-256, 2013.

[17] S. A. Yang and J. R. Birge, "Trade credit, risk sharing, and inventory financing portfolios," Management Science, 2017, https://doi.org/10.1287/mnsc.2017.2799.

[18] B. Jing, X. Chen, and G. G. Cai, "Equilibrium financing in a distribution channel with capital constraint," Production and Operations Management, vol. 21, no. 6, pp. 1090-1101, 2012.

[19] X. Chen, "A model of trade credit in a capital-constrained distribution channel," International Journal of Production Economics, vol. 159, pp. 347-357, 2015.

[20] G. G. Cai, X. Chen, and Z. Xiao, "The roles of bank and trade credits: theoretical analysis and empirical evidence," Production and Operations Management, vol. 23, no. 4, pp. 583-598, 2014.

[21] B. Zhang, D. D. Wu, and L. Liang, "Optimal option ordering and pricing decisions with capital constraint and default risk," IEEE Systems Journal, vol. 11, no. 3, pp. 1537-1547, 2017.

[22] L. Jiang and Z. Hao, "Alleviating supplier's capital restriction by two-order arrangement," Operations Research Letters, vol. 42, no. 6-7, pp. 444-449, 2014.

[23] B. Wang, D.-C. Huang, H.-y. Li, and J.-Y. Ding, "Optimal decisions and financing strategies selection of supply chain with capital constraint," Mathematical Problems in Engineering, vol. 2016, Article ID 6597259, 14 pages, 2016.

[24] N. Yan, H. Dai, and B. Sun, "Optimal bi-level Stackelberg strategies for supply chain financing with both capital-constrained buyers and sellers," Applied Stochastic Models in Business and Industry, vol. 30, no. 6, pp. 783-796, 2014.

[25] P. Kouvelis and W. Zhao, "Who should finance the supply chain? Impact of credit ratings on supply chain decisions," Manufacturing \& Service Operations Management, vol. 20, no. 1, pp. 19-35, 2018.

[26] W. Jiang and X. Chen, "Optimal strategies for low carbon supply chain with strategic customer behavior and green technology investment," Discrete Dynamics in Nature and Society, Art. ID 9645087, 13 pages, 2016.

[27] C. Ma, X. Liu, H. Zhang, and Y. Wu, "A green production strategies for carbon-sensitive products with a carbon cap policy," Advances in Production Engineering \& Management, vol. 11, no. 3, pp. 216-226, 2016.

[28] S. Du, J. Zhu, H. Jiao, and W. Ye, "Game-theoretical analysis for supply chain with consumer preference to low carbon," International Journal of Production Research, vol. 53, no. 12, pp. 3753-3768, 2015.
[29] Q. Wang, D. Zhao, and L. He, "Contracting emission reduction for supply chains considering market low-carbon preference," Journal of Cleaner Production, vol. 120, pp. 72-84, 2016.

[30] J. Qin, L. Ren, and L. Xia, “Carbon emission reduction and pricing strategies of supply chain under various demand forecasting scenarios," Asia-Pacific Journal of Operational Research, vol. 34, no. 1, Article ID 1740005, 27 pages, 2017.

[31] S. Du, L. Hu, and L. Wang, "Low-carbon supply policies and supply chain performance with carbon concerned demand," Annals of Operations Research, vol. 255, no. 1-2, pp. 569-590, 2017.

[32] L. Xu, C. Wang, and H. Li, "Decision and coordination of lowcarbon supply chain considering technological spillover and environmental awareness," Scientific Reports, vol. 7, no. 1, 2017.

[33] S. Chen, X. Wang, Y. Wu, and F. Zhou, "Pricing policies of a dual-channel supply chain considering channel environmental sustainability," Sustainability, vol. 9, no. 3, p. 382, 2017.

[34] J. Ji, Z. Zhang, and L. Yang, "Carbon emission reduction decisions in the retail-/dual-channel supply chain with consumers' preference," Journal of Cleaner Production, vol. 141, pp. 852-867, 2017.

[35] Q. Bai, M. Chen, and L. Xu, "Revenue and promotional costsharing contract versus two-part tariff contract in coordinating sustainable supply chain systems with deteriorating items," International Journal of Production Economics, vol. 187, pp. 85101, 2017.

[36] Y. Wang, W. Chen, and B. Liu, "Manufacturing/remanufacturing decisions for a capital-constrained manufacturer considering carbon emission cap and trade," Journal of Cleaner Production, vol. 140, pp. 1118-1128, 2017.

[37] S. An and J. Yao, "The optimal quilibrium of the capital constrained green supply chain under bank credit," in Proceedings of the 2016 International Conference on Logistics, Informatics and Service Sciences (LISS), pp. 1-6, Sydney, Australia, July 2016.

[38] E. Cao and M. Yu, "Trade credit financing and coordination for an emission-dependent supply chain," Computers \& Industrial Engineering, vol. 119, pp. 50-62, 2018.

[39] L. Yang, Y. Chen, and J. Ji, "Cooperation modes of operations and financing in a low-carbon supply chain," Sustainability, vol. 10, no. 3, p. 821, 2018. 


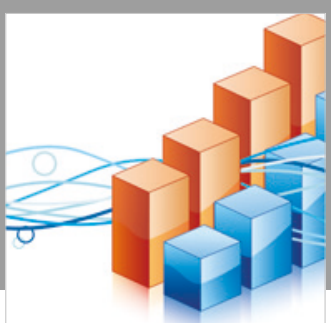

Advances in

Operations Research

\section{-n-m}
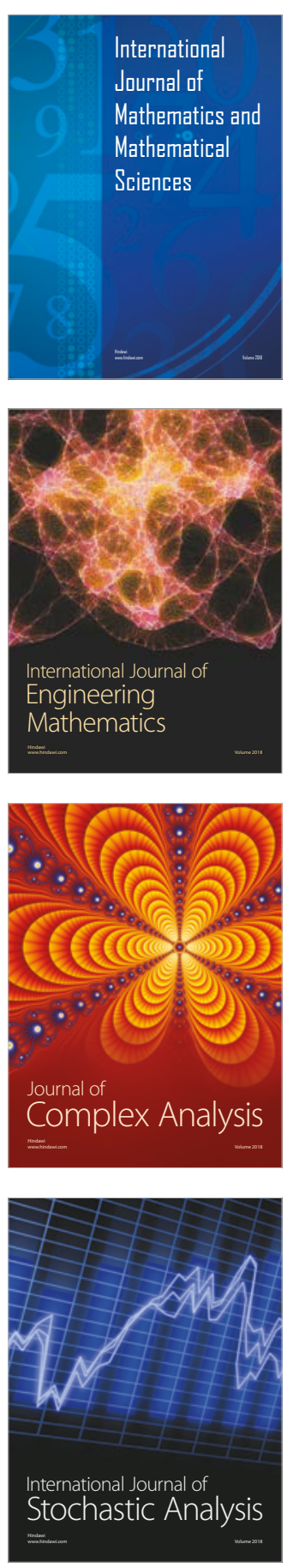
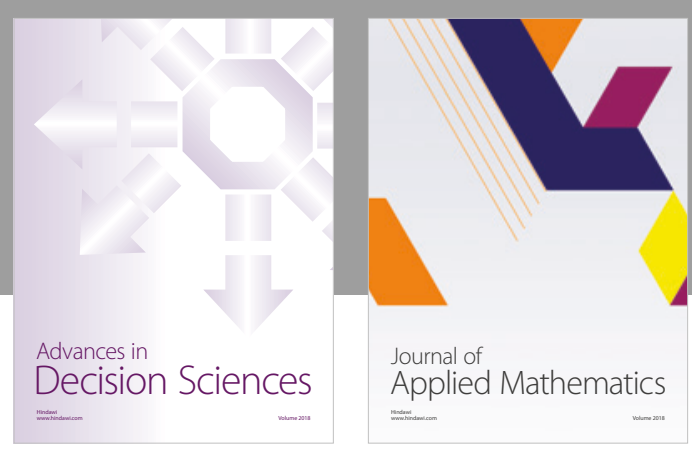

Journal of

Applied Mathematics
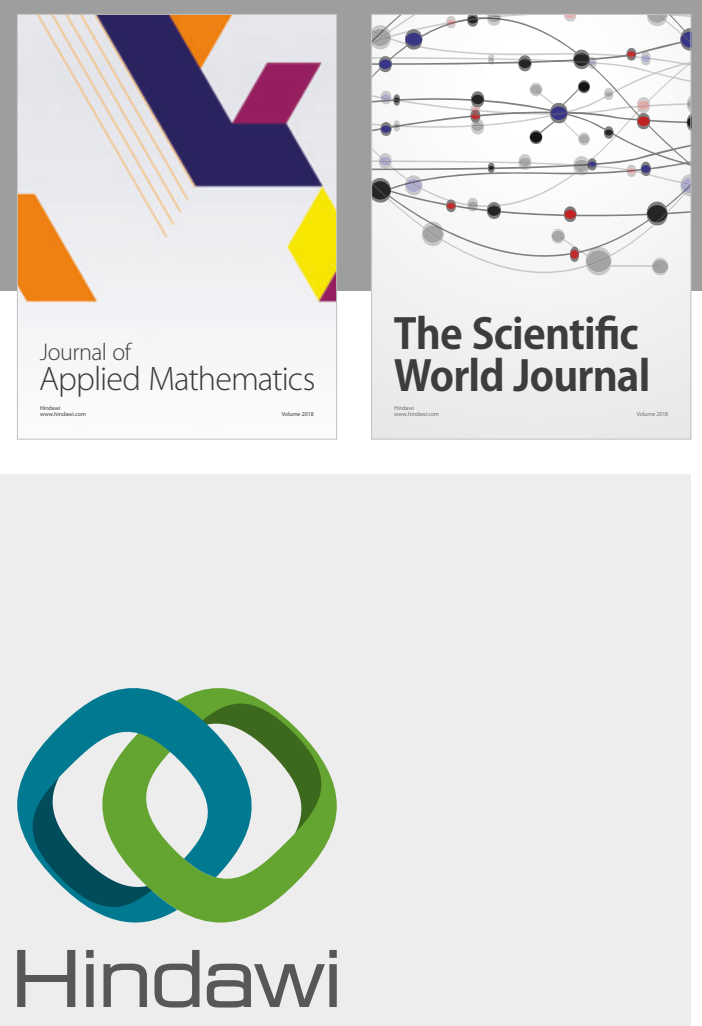

Submit your manuscripts at

www.hindawi.com

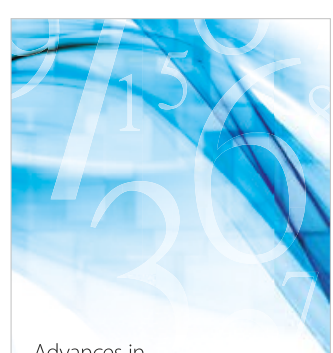

Advances in
Numerical Analysis
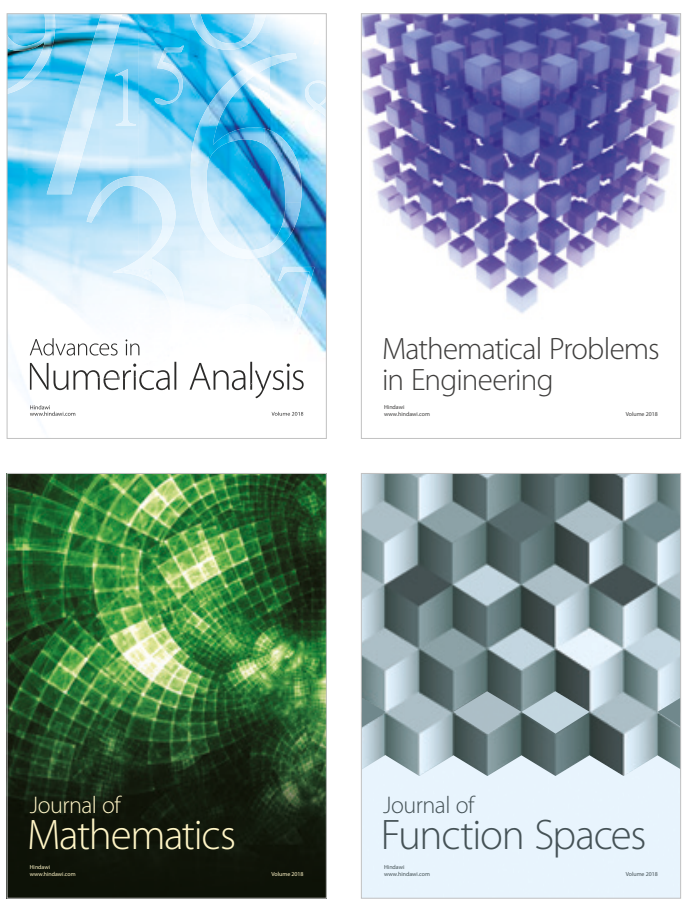

Mathematical Problems in Engineering

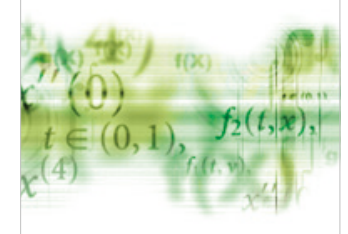

International Journal of

Differential Equations

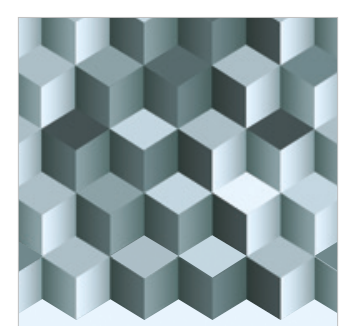

Journal of

Function Spaces

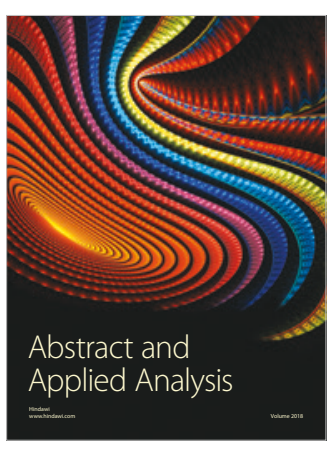

The Scientific

World Journal

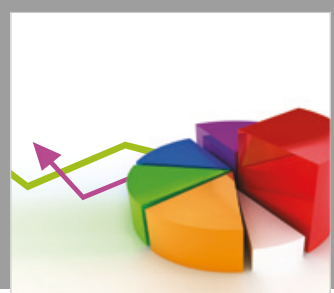

Journal of

Probability and Statistics
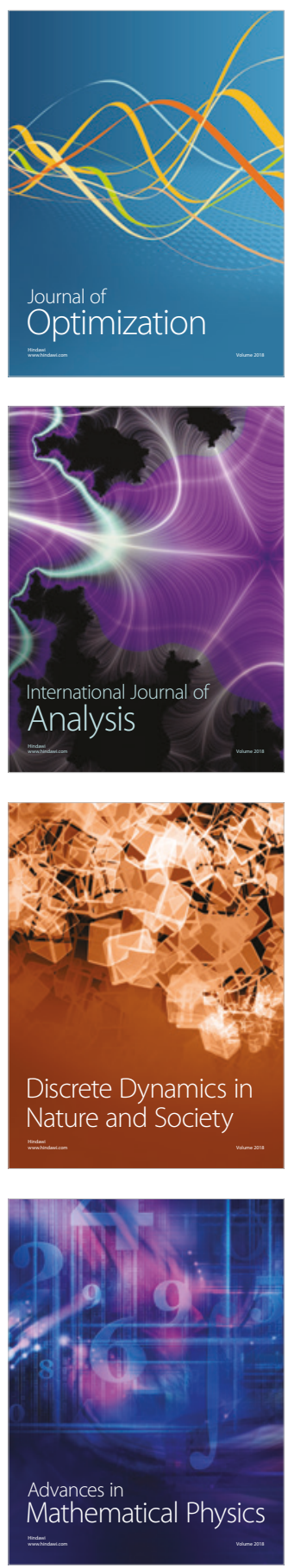